\title{
Chronic Exposure to High Altitude and Job Burnout Among Chinese Military Personnel at Qinghai-Tibet Plateau: The Mediating Effect of Fatigue and Moderating Effect of Deployment Duration
}

\author{
Zhi-hao Tu \\ Second Military Medical Universuty \\ Li Peng \\ Second Military Medical University \\ Jing-wen He \\ Second Military Medical University \\ Xing-hua Shen ( $\sim$ shenxhsci@sina.com )
}

\section{Research}

Keywords: High altitude, Job burnout, Fatigue, Mediation, Moderation, Military personnel

Posted Date: June 16th, 2020

DOI: https://doi.org/10.21203/rs.3.rs-34797/v1

License: (c) (i) This work is licensed under a Creative Commons Attribution 4.0 International License.

Read Full License 


\section{Abstract}

Background: Job burnout among military personnel is associated with many negative consequence including depression, various forms of job withdrawal, and poor job performance. The present study aimed to investigate how chronic exposure to HA, fatigue, and deployment duration may influence burnout among Chinese military personnel.

Methods: Military plateau drivers at Golmud (average altitude: $2,890 \mathrm{~m}$ ) as high altitude group $(\mathrm{N}=194)$ and military drivers at Fuzhou (average altitude: $84 \mathrm{~m})$ as low altitude group $(N=190)$ completed the selfadministrated questionnaires. Path analysis with ordinary least squares regression procedures were used to test the mediating effect of fatigue and moderating effect of deployment duration.

Results: A simple mediation from altitude to burnout through fatigue was supported by the results. Military personnel at high altitude experienced severer fatigue than those at low altitude $(B=1.215, t=$ $4.303, p<0.001)$, and fatigue in turn caused greater job burnout $(B=0.347, t=6.132, p<0.001)$. The mediating effect of fatigue was significant $(M=0.421, \mathrm{Boot} L L C l=0.207$, Boot $\mathrm{ULCl}=0.668)$ and explained $15.21 \%$ of the total effect of altitude on burnout. However, the moderating effects of deployment duration were not supported in the present study.

Conclusion: The problem of job burnout among military personnel on the plateau may be diminished by relieving their mental and physical fatigue induced by chronic exposure to high altitude and increasing the number of vacation days away from plateau.

\section{Background}

Job burnout is characterized by exhaustion, cynicism, and lack of achievement and productivity at work that mainly occurs among people-oriented professions [1]. Job burnout is associated with many negative consequences, such as depression, various forms of job withdrawal, and poor job performance [2, 3]. In recent years, job burnout among military personnel has been attracting more and more attention from scholars. Abundant studies showed that military personnel were at great risk of developing burnout $[4,5]$. However, most of the previous studies focused on military medical workers $[4,6,7]$. The prevalence of job burnout and the risk factors among military personnel in combat troops are still unclear. From the view of job demand-resource (JD-R) model, military personnel in combat troops had high job demands and absence of job resources [8]. On one hand, they are faced with huge stress and heavy workload. On the other hand, they have less social support. The unbalance of job demands and resources may result in burnout [8]. Military personnel deployed at high altitude (HA) face more stress and less support than those at low altitude (LA). Military personnel at HA suffer from hypoxia, harsh natural environment, monotonous work and life, far away from family and friends, and lack of supplies. These physical and mental deprivations make them more prone to negative emotions [9].

Previous studies have demonstrated that chronic exposure to HA may cause both physical and mental fatigue, and hypoxia at HA may play an important role in this process $[10,11]$. Clinically, a syndrome 
called chronic mountain sickness (CMS) is a highly prevalent progressive incapacitating syndrome in $\mathrm{HA}$ regions all over the world [12]. About $5-10 \%$ of HA residents are at risk of developing CMS $[12,13]$. CMS is a disease that develops after prolonged residence at $\mathrm{HA}$, which is characterized by hypoxemia, headache, breathlessness, sleep disturbances, physical and mental fatigue [14]. China has more than 3000 kilometers of national borderline on the plateau, mostly on the Qinghai-Tibet plateau. For China, Tibet plateau is of great military strategic value. According to China's military service system, conscripts assigned to the plateau should serve there for at least 2 years. For military officers, many of them serve at plateau for many years. Some of them even get married and raise their children on the plateau. Thus, relatively high prevalence of fatigue symptoms were reported among them [16].

Abundant studies showed that there was a consistent association between fatigue and burnout [16, 17]. Basinska et al. [18] found that emotion mediated the relationship between fatigue and burnout. Specifically, low-arousal negative emotions were partial mediators between fatigue and exhaustion, and high-arousal negative and positive emotions partially mediated the association between fatigue and cynicism [18]. A prospective cohort study found that prolonged fatigue and burnout influenced each other in the manner of a "downward spiral" [19]. According to the above literature review, it is reasonable to speculate that there is an association between chronic exposure to HA and job burnout, and fatigue may play a mediating role in this process. More interestingly, previous study indicated that burnout and fatigue were positively related with tenure years [20-22]. Thus, the deployment duration at HA may have a moderating effect between altitude and fatigue as well as altitude and burnout.

The present study aimed to clarify the relationship between chronic exposure to HA and job burnout. Based on previous studies, we posit the following hypotheses:

H1: Military personnel serving at HA report more symptoms of job burnout.

$\mathrm{H} 2$ : Fatigue is positively associated with burnout and mediates the association between altitude and burnout.

H3: Deployment duration moderates the direct and the indirect effect of altitude on burnout through fatigue, ie., the difference of severity of burnout between military personnel at HA and those at LA is larger when their deployment duration is long, and smaller when their deployment duration is short.

The proposed theoretical model to be tested is portrayed in Fig. 1.

\section{Methods}

\section{Sample and procedure}

The study was reviewed and approved by the Review Board of the Second Military Medical University. The sample consisted of two parts: HA group includes plateau drivers from a transportation regiment stationed at Golmud (average altitude: 2,890 m), Qinghai Province; LA group included drivers from a 
transportation regiment stationed at Fuzhou (average altitude: $84 \mathrm{~m}$ ), Fujian province. A short selfadministered questionnaires was distributed to each participant and retrieved by researchers after 30 minutes during July and August 2016. 200 plateau drivers in Golmud and 200 drivers in Fujian were selected. Written informed consent was obtained from each subject before participating in this study. All selected drivers were male. Selected drivers with the following conditions were excluded: (1) born, growing or living at HA (>500 m) before enlisted; (2) for LA group, had gone to HA (>500 m) in the recent year; (3) for HA group, left the plateau in the recent 3 months. Finally, 194 HA group participants and 190 LA group participants completed the questionnaires (Fig. 2).

\section{Measures}

\section{Demographic and working characteristics}

Age, altitude, deployment duration at the present base, educational level, marital status, only child or not, and military rank were obtained in this study. Deployment duration was recorded in months, and in turn categorized as ' $\leq 12$ months', '12 24 months', '>24 months'. 'Education' was categorized as 'Secondary school', 'High school', 'Junior college', and 'Undergraduate or above'. 'Marital status' was categorized as 'Single', 'Married'. 'Only child or not' was categorized as 'Yes' and 'Not'. 'Military rank' was categorized as 'Private' and 'Non-commissioned officer'.

\section{Job burnout}

Maslach Burnout Inventory - General Survey (MBI-GS) was used to measure burnout of the participants [23]. This instrument includes three subscales (emotional exhaustion, cynicism, and professional efficacy). All 15 items were scored on a Likert scale from 0 (never) to 6 (every day). The following equation is used to produce the weighted sum score of the scale: $0.40 \times$ exhaustion $+0.30 \times$ cynicism + $0.30 \times$ professional efficacy $[24,25]$. The Chinese version of MBI-GS has been used widely in Chinese population and demonstrated satisfactory reliability and validity [26]. In the present study, the Cronbach's alpha coefficient is 0.91 .

\section{Fatigue}

Fatigue was measured with 14-item Fatigue Scale (FS-14) [27], which was proved to be valid and reliable in China $[28,29]$. The FS-14 includes 14 yes-or-no items $(0=$ no; $1=$ yes). Sample items are "Do you need to rest more?", and "Do you have difficulty concentrating?". The total score is reported and a higher score represent severer fatigue. Cronbach's alpha coefficient is 0.80 in this study.

\section{Statistical analysis}


Data analysis were performed with SPSS and the PROCESS macro developed by Hayes [30]. Altitude was treated as dichotomous variable $(1=\mathrm{HA}, 0=\mathrm{LA})$, other measures including fatigue, burnout, and deployment duration were treated as continuous variables. Descriptive statistics were computed for demographic characteristics and main study variables. Independent sample $t$ tests and $\chi^{2}$ tests were used to detect differences of variables between HA and LA group. Bivariate relations among continuous variables were tested with Pearson correlations. For testing the moderated mediation model, we took a two-step approach. First, we test a simple mediation model to assess the effect of HA exposure on burnout, and the mediating role of fatigue $(\mathrm{H} 1$ and $\mathrm{H} 2)$. Second, we introduced the proposed multicategorical moderator variable (deployment duration) into the model and tested for moderated mediation (H3). 5000 bootstrap estimates to generated $95 \%$ bias-corrected confidence intervals $(95 \% \mathrm{Cl})$ for the simple indirect effect and conditional indirect effects. If the $95 \% \mathrm{Cl}$ did not contain 0 , the indirect effect was considered significant. Conditional indirect effects of HA exposure on burnout (through fatigue) were evaluated at three different levels of deployment duration, corresponding to the 16th, 50th, and 84th percentiles recommended by Hayes [30]. Continuous variables that define the interaction term (deployment duration) were mean-centered.

\section{Results}

Table 1 showed means and standard deviations or number (percentage) of demographic and working characteristics in HA group and LA group. The differences of age, deployment duration, educational level, marital status, only child or not, and military rank were not statistically significant between two groups. Table 1 also showed that fatigue $(p<0.001)$ and burnout $(p<0.001)$ among participants in HA group were much severer than LA group. 
Table 1

Burnout, fatigue, demographic and working characteristics between HA and LA group

\begin{tabular}{|c|c|c|c|}
\hline Variables & $\begin{array}{l}\text { HA group } \\
(n=194)\end{array}$ & $\begin{array}{l}\text { LA group } \\
(n=190)\end{array}$ & $P$ value \\
\hline Age (years) & $23.76 \pm 4.09$ & $23.64 \pm 3.89$ & 0.767 \\
\hline Deployment duration (months) & $61.71 \pm 49.54$ & $64.56 \pm 45.38$ & 0.556 \\
\hline Educational level & & & 0.219 \\
\hline Secondary school & $46(23.7 \%)$ & $33(17.4 \%)$ & \\
\hline High school & $118(60.8 \%)$ & $121(63.7 \%)$ & \\
\hline Junior college & $23(11.9 \%)$ & $32(16.8 \%)$ & \\
\hline Undergraduate or above & $7(3.6 \%)$ & $4(2.1 \%)$ & \\
\hline Marital status & & & 0.458 \\
\hline Single & $147(75.8 \%)$ & $150(78.9 \%)$ & \\
\hline Married & $47(24.2 \%)$ & $40(21.1 \%)$ & \\
\hline Only child or not & & & 0.115 \\
\hline Yes & $91(46.9 \%)$ & $73(38.4 \%)$ & \\
\hline No & $103(53.1 \%)$ & $117(61.6 \%)$ & \\
\hline Military rank & & & 0.855 \\
\hline Private & $33(17.0 \%)$ & $31(16.3 \%)$ & \\
\hline Non-commissioned officer & $161(83.0 \%)$ & $159(83.7 \%)$ & \\
\hline Fatigue & $7.37 \pm 2.95$ & $6.14 \pm 2.64$ & $<0.001$ \\
\hline Burnout & $7.45 \pm 3.34$ & $4.67 \pm 3.12$ & $<0.001$ \\
\hline
\end{tabular}

The results of Pearson correlations among deployment duration, fatigue, and burnout were provided in Table 2. Here, longer deployment duration was positively associated with fatigue $(0.17, p<0.01)$ and burnout $(0.14, p<0.01)$. Also, more fatigue was linked with greater job burnout $(0.37, p<0.001)$. 
Table 2

Correlations among the continuous variables $(\mathrm{N}=384)$

\begin{tabular}{|c|c|c|c|c|}
\hline & $M \pm S D$ & Duration & Fatigue & Burnout \\
\hline Duration & $62.56 \pm 46.66$ & 1.0 & & \\
\hline Fatigue & $6.76 \pm 2.86$ & $0.17^{\star \star}$ & 1.0 & \\
\hline Burnout & $6.07 \pm 3.01$ & $0.14^{\star \star}$ & $0.37^{\star \star \star}$ & 1.0 \\
\hline \multicolumn{5}{|c|}{ 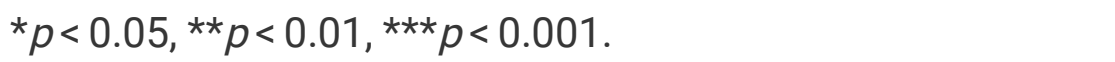 } \\
\hline
\end{tabular}

Table 3 showed the ordinary least squares regression results and bootstrap results for the simple mediation test. The total effect model showed that HA group had higher MBI-GS scores than LA group ( $B$ $=2.767, t=8.476, p<0.001)$. For mediation hypothesis, the effect of altitude on fatigue (a pathway) was significant $(B=1.215, t=4.303, p<0.001$ ), as was fatigue on burnout (b pathway, $B=0.347, t=6.132, p<$ $0.001)$. The bootstrap results with 5,000 re-sampling showed an unstandardized indirect effect of 0.421 , and $95 \% \mathrm{Cl}$ not containing $0(0.207,0.668)$, which means that the mediating effect of fatigue in the relationship between altitude and burnout was statistically significant. The mediating effect can explain $15.22 \%(0.421 / 2.767=15.22 \%)$ of the total effect of altitude on burnout.

Table 3

Ordinary least squares regression results for simple mediation $(N=384)$.

\begin{tabular}{|c|c|c|c|c|c|c|}
\hline Variable & $B$ & $S E$ & $t$ & $p$ & $L L C l$ & ULCI \\
\hline \multicolumn{7}{|l|}{ Direct and total effects } \\
\hline Altitude $\rightarrow$ Fatigue & 1.215 & 0.282 & 4.303 & $<.001$ & 0.660 & 1.770 \\
\hline Fatigue $\rightarrow$ Burnout & 0.347 & 0.057 & 6.132 & $\dot{0} 001$ & 0.236 & 0.458 \\
\hline $\begin{array}{l}\text { Altitude } \rightarrow \text { Burnout. Controlling for Fatigue } \\
\text { (direct effect) }\end{array}$ & 2.346 & 0.319 & 7.436 & $\hat{0} .001$ & 1.717 & 2.973 \\
\hline Altitude $\rightarrow$ Burnout. (total effect) & 2.767 & 0.326 & 8.476 & $\dot{0} 001$ & 2.125 & 3.408 \\
\hline \multicolumn{7}{|l|}{$\begin{array}{l}\text { Bootstrap results for Indirect Effect of Altitude } \\
\text { on Burnout }\end{array}$} \\
\hline Effect & $M$ & $S E$ & LLCl & ULCI & & \\
\hline Unstandardized & 0.421 & 0.119 & 0.207 & 0.668 & & \\
\hline Standardized & 0.120 & 0.033 & 0.060 & 0.189 & & \\
\hline \multicolumn{7}{|c|}{$\begin{array}{l}\text { Note: Unstandardized regression coefficients are reported unless noted. Bootstrap sample size = } \\
5,000 . \mathrm{LLCl}=95 \% \text { lower limit confidence interval; } \mathrm{ULCl}=95 \% \text { upper limit confidence interval (bias- } \\
\text { corrected bootstrap confidence intervals) }\end{array}$} \\
\hline
\end{tabular}


The results of moderation analysis were shown in Table 4. Not as expected, there was not significant interaction effect of deployment duration with altitude on fatigue $(B=0.003, t=0.507, p=0.603)$. The interaction effect of duration with altitude on burnout was also not significant $(B=0.008, t=0.007, p=$ 0.212 ). The main effect of duration on fatigue was significant $(B=0.009, t=0.004, p=0.035$ ), which means longer deployment duration was positively associated with fatigue controlled the influence of altitude. But, the main effect of duration on burnout was not significant $(B=0.004, t=0.005, p=0.418)$. 
Table 4

Ordinary least squares regression results for conditional indirect effect $(\mathrm{N}=384)$

\section{Outcome variable: Burnout}

$\begin{array}{|lllllll|}\text { Predictor } & \mathrm{B} & \mathrm{SE} & \mathrm{t} & \mathrm{p} & \mathrm{LLCl} & \mathrm{ULCl} \\ \text { Altitude } & 2.397 & 0.319 & 7.507 & <0.001 & 1.769 & 3.025 \\ \text { Fatigue } & 0.339 & 0.057 & 5.996 & <0.001 & 0.228 & 0.451 \\ \text { Duration } & 0.004 & 0.005 & 0.811 & 0.418 & -0.006 & 0.014 \\ \text { Altitude - duration } & 0.008 & 0.007 & 1.249 & 0.212 & -0.005 & 0.022\end{array}$

[Model $\mathrm{R}=0.507 ; \mathrm{R}^{2}=0.257 ; \mathrm{MSE}=9.271 \mathrm{~F}(4,379)=32.825 ; \mathrm{p}<$ $0.001]$

Conditional direct effect of Altitude on Burnout at different values of Duration

\begin{tabular}{lllll} 
Duration & Boot effect & Boot SE & Boot LLCl & Boot ULCl \\
14th percentile (-47.557) & 1.999 & 0.450 & 1.114 & 2.885 \\
\hline 50th percentile (-14.557) & 2.275 & 0.334 & 1.619 & 2.931 \\
84th percentile (57.443) & 2.877 & 0.500 & 1.893 & 3.861
\end{tabular}

Outcome variable: Fatigue

\begin{tabular}{lllllll|} 
Predictor & $\mathrm{B}$ & $\mathrm{SE}$ & $\mathrm{t}$ & $\mathrm{p}$ & $\mathrm{LLCl}$ & $\mathrm{ULCl}$ \\
\hline Altitude & 1.272 & 0.282 & 4.511 & $<0.001$ & 0.718 & 1.827 \\
\hline Duration & 0.009 & 0.004 & 2.113 & 0.035 & 0.001 & 0.018 \\
\hline Altitude - duration & 0.003 & 0.006 & 0.507 & 0.613 & -0.009 & 0.015
\end{tabular}

[Model $R=0.281 ; R^{2}=0.079 ;$ MSE $=7.621 F(3,380)=10.821 ; p<$ $0.001]$

Conditional indirect effect of Altitude on burnout at different values of duration

$\begin{array}{lllll}\text { Duration } & \text { Boot effect } & \text { Boot SE } & \text { Boot LLCl } & \text { Boot ULCI } \\ \text { 14th percentile (-47.557) } & 0.382 & 0.152 & \mathbf{0 . 1 0 6} & \mathbf{0 . 7 0 1} \\ \text { 50th percentile (-14.557) } & 0.416 & 0.121 & \mathbf{0 . 2 0 0} & \mathbf{0 . 6 6 9} \\ \text { 84th percentile (57.443) } & 0.491 & 0.167 & \mathbf{0 . 1 9 2} & \mathbf{0 . 8 3 8}\end{array}$

Note: Age is controlled as covariate. Unstandardized regression coefficients are reported. Bootstrap sample size $=5,000$. $\mathrm{LLCl}=95 \%$ lower limit confidence interval; $\mathrm{ULCl}=95 \%$ upper limit confidence interval (bias-corrected bootstrap confidence intervals). Deployment duration are mean-centered. 
The results of conditional direct and indirect effect of altitude on burnout were also reported in Table 4 . The results showed that the differences of fatigue and burnout at three different values (long, moderate, short) of deployment duration between HA and LA group were all significant ( $95 \% \mathrm{Cl}$ not containing zero), but the level of differences were not statistically different. The interaction effects were shown in Fig. 3. and Fig. 4.

\section{Discussion}

To our best knowledge, this was the first study that focused on job burnout among military personnel at $\mathrm{HA}$ and explored the influence of deployment duration, fatigue, and altitude on burnout. In the present study, we found that Chinese military plateau drivers reported greater job burnout than military drivers at LA. The simple mediation test also showed that high altitude had a direct effect on job burnout even if the influence of fatigue was controlled. The mediating effect of fatigue in the relationship between altitude and burnout was supported by this sample. However, the expected moderating effect of deployment duration was not supported by this sample.

The observed association between altitude and burnout resulted from many conditions. First, due to hypoxia and complicated terrain on the plateau, the workload of drivers on the plateau are much heavier than that at sea level in the case of equal number of transportation tasks. The heavy workload is a risk factor of job burnout [31-33]. Monotonous landscape along the way during transportation duty on the plateau makes plateau drivers feel bored. Recent studies found that boredom was associated with burnout [34,35]. Different culture and customs, far away from home, and difficulties in contacting with friends and family may cause plateau drivers lack of social support. There has been a consistent and great number of evidence that a lack of social support may lead to burnout $[3,36,37]$.

In this study, we also found that military personnel on the plateau complained more fatigue than those at sea level. This result of more fatigue induced by exposure to HA was in line with previous study [38, 39]. Hypoxia may play an important role in the effect of exposure to HA on development of mental and physical fatigue $[10,11]$. Furthermore, a positive association between fatigue and burnout was also found in this study. Chronic fatigue and burnout have many similarities in their symptoms, and they even co-occur frequently $[40,41]$. Actually, they are reciprocal causation influencing each other [19].

Military personnel with longer deployment duration reported more fatigue in this study, which agreed the positive relation between tenure and fatigue [21, 22]. However, military personnel on the plateau did not complain more burnout over time, although the Pearson correlation between deployment duration and burnout was significant. This may result from the mediating effect of fatigue. Longer deployment duration made military personnel experience more fatigue, which in turn cause severer burnout. Thus, when the effect of fatigue was controlled, there was no significant association between deployment duration and burnout. Furthermore, the expected moderation effects of deployment duration were not supported by this study. In other words, the observed differences of fatigue and burnout between HA group and La group did not become larger over time. Two reasons can explain these phenomenon. First, 
the effect of HA may exist a critical period which is much shorter than 61.71 months (the average duration of plateau drivers in this study). In this critical period, military personnel, as a newcomer on the plateau, may experience rapidly deteriorating negative mood (like exhaustion in burnout) and fatigue [11, 42]. But after this acute period, the development of fatigue and burnout among plateau drivers is mild, which do not differ from the pattern at sea level. Second, the effect of selection and promotion mechanism in army may confound the results. On one hand, only those well-behaved drivers can stay in the army after the end of their two-year compulsory service, which means that drivers with poor performance caused by fatigue and burnout may be weeded out. One the other hand, those who volunteered to stay in the army after two-year compulsory service may experience less fatigue and burnout. The survivor bias may exist in this study. Thus, long deployment duration of selected military personnel may mask the moderating effect.

Several limitations of the present study must be addressed. First, this was a cross-sectional study. Thus, the simple mediation model cannot be regarded as a causal model. Further longitudinal repeated measurement design study should be conducted. Second, most of the participants at HA served in the army for more than 12 months, which may miss the critical period of psychological and physical changed induced by exposure to HA.

\section{Conclusion}

Military personnel experience more fatigue and job burnout than those serving at sea level. The problem of job burnout among military personnel at HA may be diminished by relieving their mental and physical fatigue induced by chronic exposure to high altitude and increasing the number of vacation days away from plateau.

\section{Abbreviations}

FS-14: 14-item Fatigue Scale; OR: odds ratio; Cl: confidence interval; HA: high altitude; LA: low altitude; CMS: Chronic Mountain Sickness; LLCl: 95\% lower limit confidence interval; ULCl: 95\% upper limit confidence interval; MBI-GS: Maslach Burnout Inventory - General Survey;

\section{Declarations}

\section{Ethics approval and consent to participate}

The protocols were approved by the Review Board of the Second Military Medical University. Written informed consent was obtained from each subject before participating in this study.

\section{Consent for publication}

Not applicable. 


\section{Availability of data and materials}

The datasets generated and/or analyzed during the current study are not publicly available due to the potential sensitive nature of military healthcare data.

\section{Competing interests}

The authors declare that they have no competing interests.

\section{Funding}

12th Five-Year Plan, Grant/Award Number: AWS12J002; People's Liberation Army, China

\section{Authors' contributions}

LP and XS developed the study design. LP collected the data. LP, ZT and JH analyzed and interpreted the data. $\mathrm{ZT}$ and $\mathrm{JH}$ conducted a literature search and wrote the manuscript. All authors read and approved the final manuscript.

\section{Acknowledgements}

Thank a lot to my beloved wife and hard-working colleague: Jing-wen He.

\section{References}

1. Maslach C. What have we learned about burnout and health? Psychol Heal. 2001;16: 607-611. doi:10.1080/08870440108405530

2. Bianchi R, Schonfeld IS, Laurent E. Burnout-depression overlap: A review. Clin Psychol Rev. 2015;36: 28-41. doi:10.1016/j.cpr.2015.01.004

3. Maslach C, Schaufeli WB, Leiter MP. Job burnout. Ann Rev Psycho. 2001:397-422. doi: 10.1146/annurev.psych.52.1.397

4. Stearns S, Shoji K, Benight CC. Burnout among US military behavioral health providers. J Nerv Ment Dis. 2018;206: 398-409. doi:10.1097/NMD.0000000000000823

5. Simons BS, Foltz PA, Chalupa RL, Hylden CM, Dowd TC, Johnson AE. Burnout in U.S. Military Orthopaedic Residents and Staff Physicians. Mil Med. 2016;181: 835-839. doi:10.7205/milmed-d15-00325

6. Adler AB, Adrian AL, Hemphill M, Scaro NH, Sipos ML, Thomas JL. Professional Stress and Burnout in U.S. Military Medical Personnel Deployed to Afghanistan. Mil Med. 2017;182: e1669-e1676. 
doi:10.7205/milmed-d-16-00154

7. Ballenger-Browning KK, Schmitz KJ, Rothacker JA, Hammer PS, Webb-Murphy JA, Johnson DC. Predictors of Burnout Among Military Mental Health Providers. Mil Med. 2011;176: 253-260. doi:10.7205/milmed-d-10-00269

8. Bakker AB, Demerouti E. The Job Demands-Resources model: State of the art. J Manag Psychol. 2007;22: 309-328. doi:10.1108/02683940710733115

9. Wang J, Zhou Y, Liang Y, Liu Z. A large sample survey of tibetan people on the qinghai-tibet plateau: Current situation of depression and risk factors. Int J Environ Res Public Health. 2020;17: 1-15. doi:10.3390/ijerph17010289

10. Fan JL, Kayser B. Fatigue and Exhaustion in Hypoxia: The Role of Cerebral Oxygenation. High Alt Med Biol. 2016;17: 72-84. doi:10.1089/ham.2016.0034

11. Stavrou NAM, Debevec T, Eiken O, Mekjavic IB. Hypoxia worsens affective responses and feeling of fatigue during prolonged bed rest. Front Psychol. 2018;9: 1-10. doi:10.3389/fpsyg.2018.00362

12. Villafuerte FC, Corante N. Chronic Mountain Sickness: Clinical Aspects, Etiology, Management, and Treatment. High Alt Med Biol. 2016;17: 61-69. doi:10.1089/ham.2016.0031

13. León-Velarde F, Maggiorini M, Reeves JT, Aldashev A, Asmus I, Bernardi L, et al. Consensus statement on chronic and subacute high altitude diseases. High Alt Med Biol. 2005;6: 147-157. doi:10.1089/ham.2005.6.147

14. Gamboa JL, Caceda R, Arregui A. Is depression the link between suicide and high altitude? High Alt Med Biol. 2011;12: 403-404. doi:10.1089/ham.2011.1014

15. Tian YQ, Chen XX, Cai Y, Huang WR, Meng FY, Xie YJ, et al. Relationship of military fatigue with psychological stress $₫$ stress perception and self-efficacy in soldiers from $2^{\text {nd }}$ Artillery Corps during plateau encamping. J Third Mil Med Univ. 2015; 37 (21): 2156-2159. doi: 10.16016/j.10005404.201503128

16. Raftopoulos $V$, Charalambous $A$, Talias $M$. The factors associated with the burnout syndrome and fatigue in Cypriot nurses: A census report. BMC Public Health. 2012;12. doi:10.1186/1471-2458-12457

17. Coetzee N, Maree DJF, Smit BN. The relationship between chronic fatigue syndrome, burnout, job satisfaction, social support and age among academics at a tertiary institution. Int J Occup Med Environ Health. 2019;32(1):75-85. doi:10.13075/ijomeh.1896.01274

18. Basinska BA, Wiciak I, Dåderman AM. Fatigue and burnout in police officers: The mediating role of emotions. Policing. 2014;37: 665-680. doi:10.1108/PIJPSM-10-2013-0105

19. Leone SS, Huibers MJH, Knottnerus JA, Kant I. The temporal relationship between burnout and prolonged fatigue: A 4-year prospective cohort study. Stress Heal. 2009;25: 365-374. doi:10.1002/smi.1280

20. Jakimowicz S, Perry L, Lewis J. Compassion satisfaction and fatigue: A cross-sectional survey of Australian intensive care nurses. Aust Crit Care. 2018;31: 396-405. doi:10.1016/j.aucc.2017.10.003 
21. Daneshmandi H, Choobineh A, Ghaem H. Psychometric Properties of the Persian Version of the "Multidimensional Assessment of Fatigue Scale". Int J Prev Med. 2019;10:53. doi:10.4103/ijpvm.IJPVM_172_17

22. Guan S, Xiaerfuding X, Ning L, Lian Y, Jiang Y, Liu J, et al. Effect of job strain on job burnout, mental fatigue and chronic diseases among civil servants in the Xinjiang Uygur autonomous region of China. Int J Environ Res Public Health. 2017;14: 1-15. doi:10.3390/ijerph14080872

23. Schaufeli WB, Taris TW. The conceptualization and measurement of burnout: Common ground and worlds apart. Work Stress. 2005;19: 256-262. doi:10.1080/02678370500385913

24. Kalimo R, Pahkin K, Mutanen P, Toppinen-Tanner S. Staying well or burning out at work: Work characteristics and personal resources as long-term predictors. Work Stress. 2003;17: 109-122. doi:10.1080/0267837031000149919

25. Wen J, Cheng Y, Hu X, Yuan P, Hao T, Shi Y. Workload, burnout, and medical mistakes among physicians in China: A cross-sectional study. Biosci Trends. 2016;10: 27-33. doi:10.5582/bst.2015.01175

26. Wang Y, Chang Y, Fu J, Wang L. Work-family conflict and burnout among Chinese female nurses: The mediating effect of psychological capital. BMC Public Health. 2012;12. doi:10.1186/1471-2458-12915

27. Chalder T, Berelowitz G, Pawlikowska T, et al. Development of a fatigue scale. J Psychosom Res. 1993;37(2):147-153. doi:10.1016/0022-3999(93)90081-p

28. Jing MJ, Lin WQ, Wang Q, Wang JJ, Tang J, Jiang ES, et al. Reliability and construct validity of two versions of Chalder fatigue scale among the general population in mainland China. Int J Environ Res Public Health. 2016;13. doi:10.3390/ijerph13010147

29. Yang JS, Xu HL, Chen PP, Sikandar A, Qian MZ, Lin HX, et al. Ataxic Severity Is Positively Correlated With Fatigue in Spinocerebellar Ataxia Type 3 Patients. Front Neurol. 2020;11: 1-6. doi:10.3389/fneur.2020.00266

30. Hayes AF. Introduction to Mediation, Moderation, and Conditional Process Analysis: A RegressionBased Approach. Guilford, New York. 2013.

31. Pastores SM, Kvetan V, Coopersmith CM, Farmer JC, Sessler C, Christman JW, et al. Workforce, Workload, and Burnout among Intensivists and Advanced Practice Providers: A Narrative Review. Crit Care Med. 2019;47: 550-557. doi:10.1097/CCM.0000000000003637

32. Barbosa FT, Leão BA, Tavares GMS, dos Santos JGRP. Burnout syndrome and weekly workload of on-call physicians: Cross-sectional study I Síndrome de burnout e carga horária semanal de trabalho em médicos plantonistas: Estudo transversal. Sao Paulo Med J. 2012;130. doi:10.1590/S151631802012000500003

33. Portoghese I, Galletta M, Coppola RC, Finco G, Campagna M. Burnout and workload among health care workers: The moderating role of job control. Saf Health Work. 2014;5: 152-157. doi:10.1016/j.shaw.2014.05.004 
34. Sousa T, Neves P. Two Tales of Rumination and Burnout: Examining the Effects of Boredom and Overload. Applied Psychology. 2020. doi:10.1111/apps.12257

35. Sulea C, van Beek I, Sarbescu P, Virga D, Schaufeli WB. Engagement, boredom, and burnout among students: Basic need satisfaction matters more than personality traits. Learn Individ Differ. 2015;42: 132-138. doi:10.1016/j.lindif.2015.08.018

36. Boland LL, Mink PJ, Kamrud JW, Jeruzal JN, Stevens AC. Social Support Outside the Workplace, Coping Styles, and Burnout in a Cohort of EMS Providers From Minnesota. Work Heal Saf. 2019;67: 414-422. doi:10.1177/2165079919829154

37. Hamaideh SH. Burnout, social support, and job satisfaction among jordanian mental health nurses. Issues Ment Health Nurs. 2011;32: 234-242. doi:10.3109/01612840.2010.546494

38. Marillier M, Arnal PJ, Le Roux Mallouf T, Rupp T, Millet GY, Verges S. Effects of high-altitude exposure on supraspinal fatigue and corticospinal excitability and inhibition. Eur J Appl Physiol. 2017;117: 1747-1761. doi:10.1007/s00421-017-3669-y

39. Amann M, Goodall S, Twomey R, Subudhi AW, Lovering AT, Roach RC. AltitudeOmics: On the consequences of high-altitude acclimatization for the development of fatigue during locomotor exercise in humans. J Appl Physiol. 2013;115: 634-642. doi:10.1152/japplphysiol.00606.2013

40. Leone SS, Wessely S, Huibers MJH, Knottnerus JA, Kant I. Two sides of the same coin? On the history and phenomenology of chronic fatigue and burnout. Psychol Heal. 2011;26: 449-464. doi:10.1080/08870440903494191

41. Huibers MJH, Beurskens AJHM, Prins JB, Kant IJ, Bazelmans E, Van Schayck CP, et al. Fatigue, burnout, and chronic fatigue syndrome among employees on sick leave: Do attributions make the difference? Occup Environ Med. 2003;60. doi:10.1136/oem.60.suppl_1.i26

42. Bardwell WA, Ensign WY, Mills PJ. Negative mood endures after completion of high-altitude military training. Ann Behav Med. 2005;29: 64-69. doi:10.1207/s15324796abm2901_9

\section{Figures}

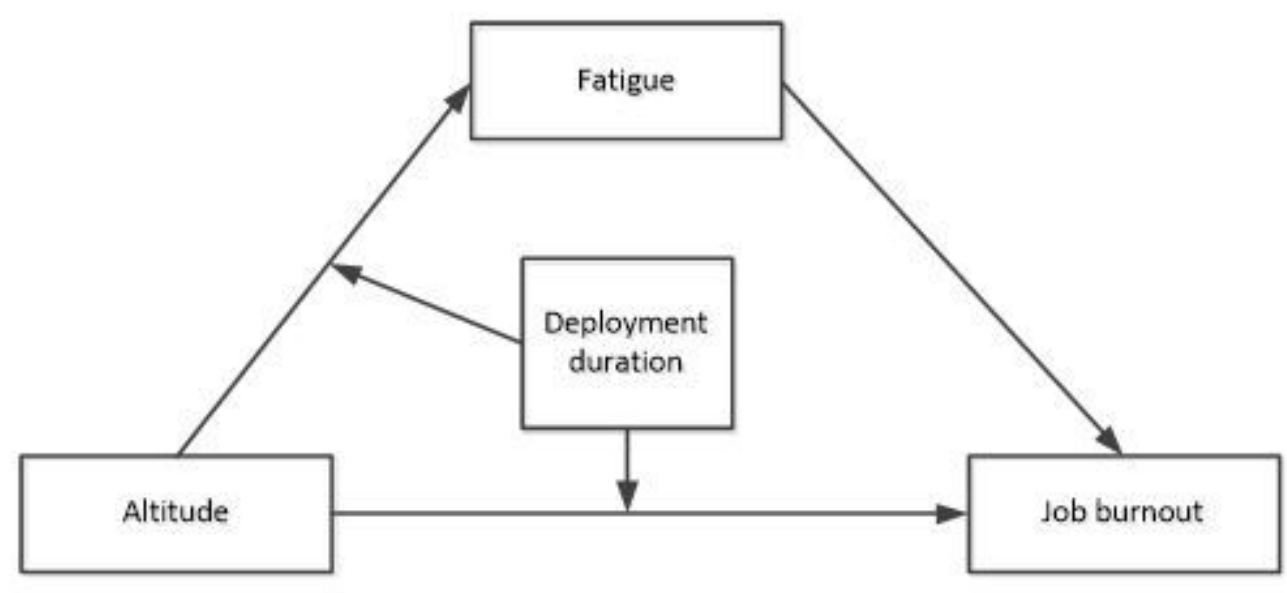

Page 15/18 
Figure 1

The proposed theoretical moderated-mediation model.

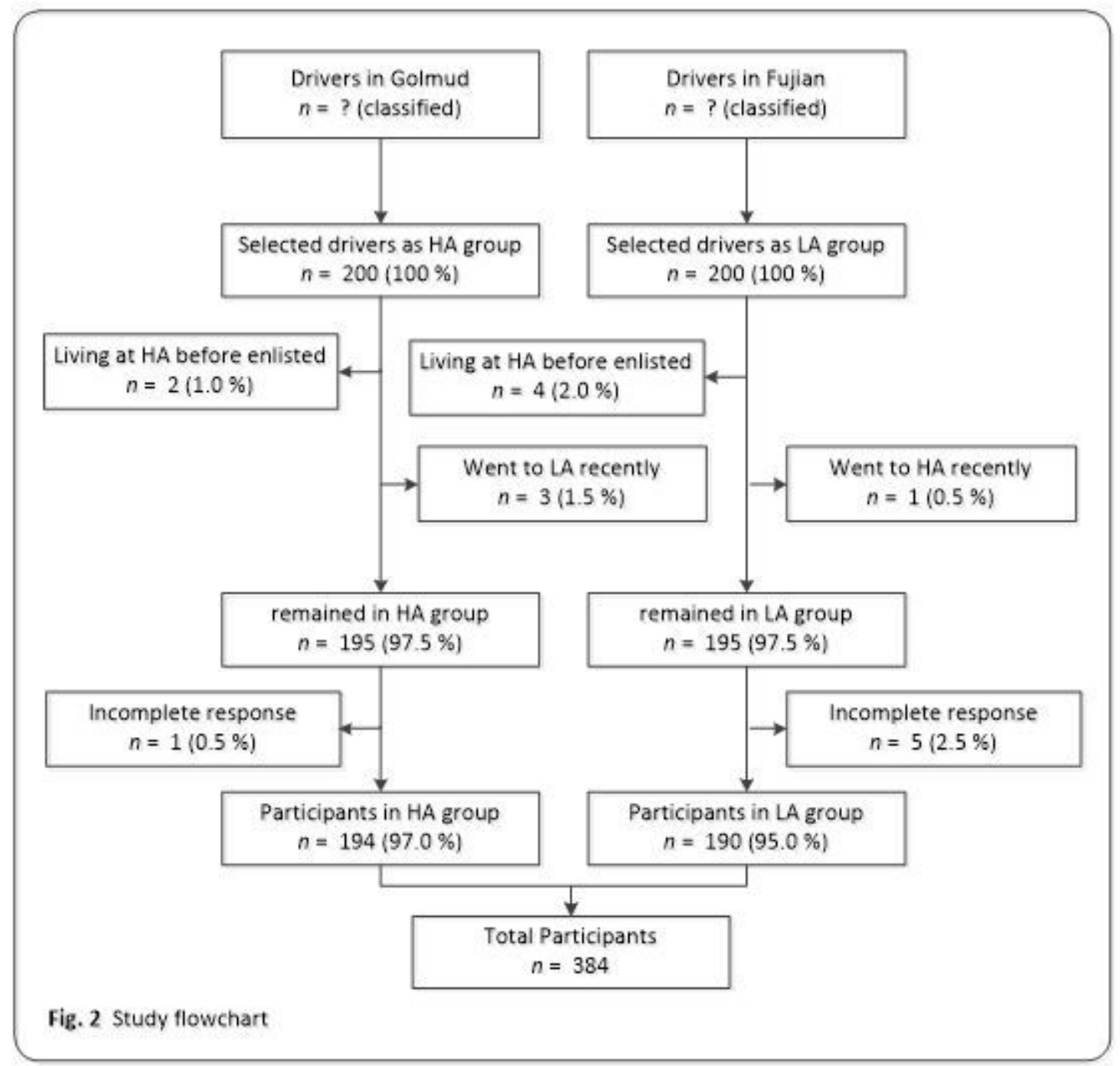

Figure 2

Study flowchart 


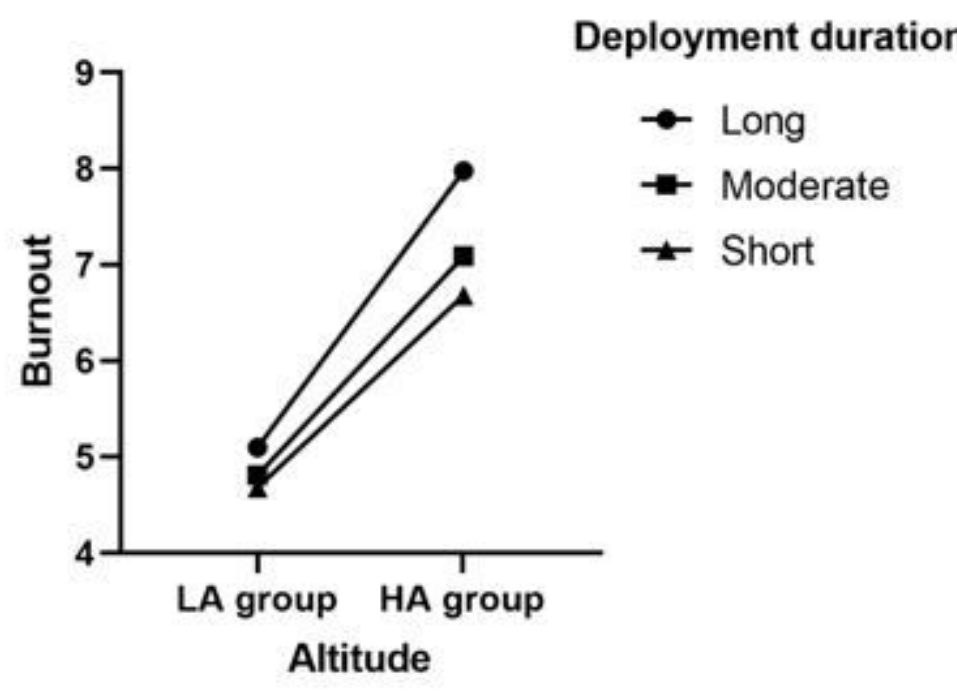

Figure 3

Altitude and Burnout at different levels of Deployment duration

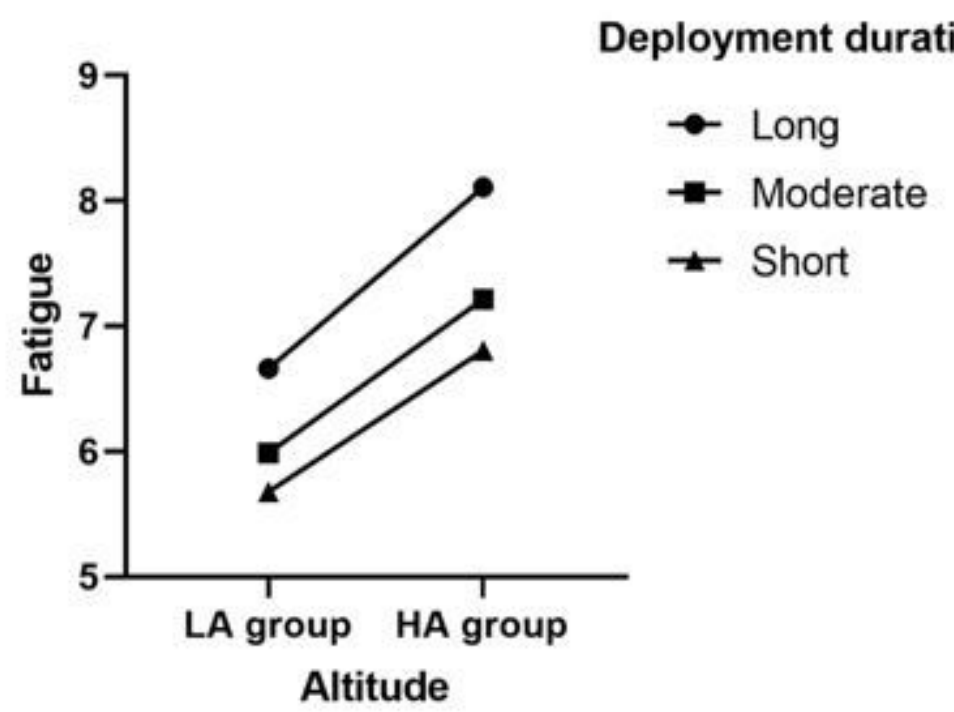

Figure 4

Altitude and Fatigue at different levels of Deployment duration 


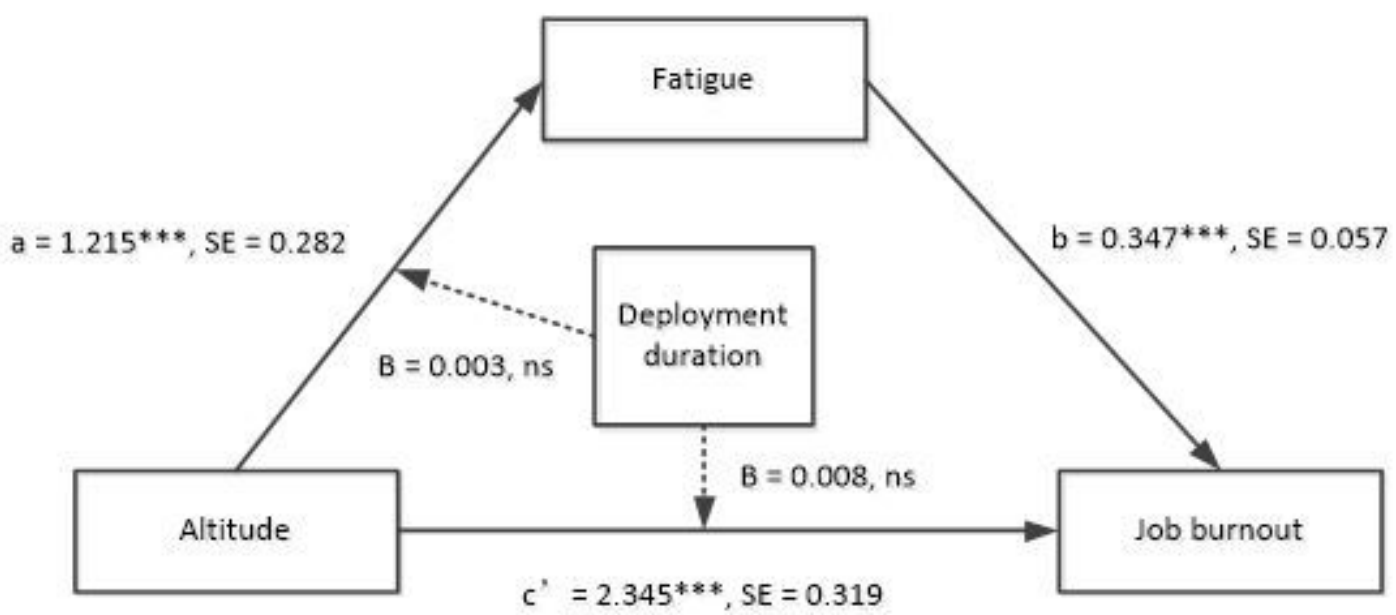

\section{Figure 5}

Final model showing only simple mediation with no moderation; Fatigue mediated the influence of altitude on Burnout. ns = not statistically siginificant 